\title{
Acrolein Dimer as a Marker for Direct Detection of Acrolein in Wine
}

\author{
R. Bauer ${ }^{1, *}$, F. Hiten ${ }^{2}$, A.M. Crouch ${ }^{3}$, J. Kossmann ${ }^{4}$, B.V. Burger ${ }^{5}$
}

(1) Institute for Microbial Biotechnology and Metagenomics, Department of Biotechnology, University of the Western Cape, Cape Town, South Africa

(2) Central Analytical Facility, Stellenbosch University, Stellenbosch, South Africa

(3) Institute of Molecular Sciences, Faculty of Science, University of the Witwatersrand, Johannesburg, South Africa

(4) Institute for Plant Biotechnology, Department of Genetics, Stellenbosch University, Stellenbosch, South Africa

(5) Department of Chemistry, Stellenbosch University, Stellenbosch, South Africa

Submitted for publication: September 2011

Accepted for publication: December 2011

Key words: acrolein, acrolein dimer, TOF, GC-MS, SPME, SEP, wine

\begin{abstract}
Acrolein is highly toxic and its presence in wine has been correlated with the development of bitterness. Analytical detection and quantification in aqueous solutions are challenging due to high reactivity and problems with chemical derivative analysis. Here we demonstrate the potential of a natural derivative, formed under conditions prevailing in wine, as a marker for acrolein detection. Solid-phase microextraction (SPME) coupled with gas chromatograph mass spectrometry (GC-MS) was validated as a technique for direct detection of the acrolein dimer. Conventional GC-MS analysis using a quadrupole mass spectrometer did not provide sufficient chromatographic resolution for the separation of the target analyte from interfering compounds. Accurate mass measurements with time-of-flight (TOF)-MS, on the other hand, allowed qualitative and quantitative measurements of the acrolein dimer. This work lays the analytical foundation for studies on the evolution of acrolein and its dimer in solution.
\end{abstract}

\section{INTRODUCTION}

Acrolein, also known as 2-propenal or acrylaldehyde, is an $\alpha, \beta$-unsaturated carbonyl compound. In its class, acrolein displays the highest reactivity with nucleophiles (Uchida et al., 1998), making it a dangerous substance for the living cell even when present in minute concentrations. Acrolein, a pulmonary toxicant and an irritant of mucous membranes (Esterbauer et al., 1991), is considered by regulatory agencies to be one of the greatest non-cancer health risks of all organic pollutants. Acrolein has furthermore been implicated in the development of bitterness upon combination with polyphenols in wine (Rentschler \& Tanner, 1951). Under the conditions prevalent during winemaking, acrolein is non-enzymatically produced by an elimination of $\mathrm{H}_{2} \mathrm{O}$ from 3-hydroxypropionaldehyde (3-HPA), a product of bacterial glycerol fermentation. Lactic acid bacteria (LAB) isolated from wine and belonging to the genus Lactobacillus have been implicated in the accumulation of 3-HPA during anaerobic glycerol fermentation (Pasteris \& Strasser de Saad, 2009; Bauer et al., 2010b).

Methodologies for determining acrolein are generally based on carbonyl-derivatising agents combined with solvent extraction (Bauer et al., 2010a). Compounds such as acrolein, which display poor chromatographic performance, high reactivity, high volatility and thermal instability, generally require derivatisation during sample preparation. While advances have been made in establishing an appropriate methodology for measuring acrolein in ambient air (Seaman et al., 2006), the analysis of liquid samples is more challenging. Problems linked to derivative analysis include instability, co-elution of other compounds, long sample collection times, and ozone interference. Not only is analytical detection complicated, but acrolein interacts with ethanol and water and, due to its high reactivity, has a low steady-state concentration in complex systems (Bauer et al., 2010a). For these reasons, few studies have evaluated its content in beverages. Levels of up to $2.8 \mathrm{mg} / \mathrm{L}$ in wine, measured after separation by distillation, have been reported, way above the threshold for acute effects in humans $(0.04$ ppm) (Bauer et al., 2010a).

Trends in the development of modern analytical extraction techniques centre on the use of adsorbents or sorbents for selective analyte extraction as alternatives to 
solvent extraction. Various systems have been developed for this purpose (Raynie, 2006), of which solid-phase microextraction (SPME) is generally preferred due to its versatility and ease of use (Arthur \& Pawliszyn, 1990). In SPME, a very small volume of sorptive phase is utilised, and thermal desorption of the enriched material takes place almost immediately. The amount of available phase conversely limits the mass of analyte extracted. Recent developments in the high-capacity sample enrichment probe (SEP) circumvent this problem (Burger et al., 1990, 2006, 2011). An SEP consists of a thin probe of inert material that is provided at one end with a short sleeve of silicone rubber for analyte sorption. As in SPME, desorption and GC separation of the volatiles run almost concurrently and no auxiliary thermal desorption and cryotrapping equipment are required (Burger et al., 2006). Few published studies report on the use of modern extraction techniques as alternatives to chemical derivatisation for the direct detection of acrolein in aqueous solution (Takamoto et al., 2001, 2004), and the studies were only successful if analysis was performed after a short contact time of the sample with acrolein.

This paper aims to establish a method that would allow studies of the evolution and transformation of acrolein and its derivatives in wine. We report on the determination of the acrolein dimer (3,4-dihydro-2H-pyran-2-carboxaldehyde), a natural derivative that might be usable as a marker for indicating the presence of acrolein in wine. The analytical approach was aimed at reducing sample preparation steps by applying sorptive sample extraction techniques, such as SPME and SEP, and direct thermal desorption. The paper validates SPME coupled to accurate mass measurements with GC-TOFMS as methodology for the direct detection of the acrolein dimer in complex matrixes such as wine. Parameters affecting the sorption of the acrolein dimer to the SPME fibre are discussed. Linearity, detection limits and precision of the procedure are evaluated.

\section{MATERIALS AND METHODS}

\section{Headspace SPME extraction and GC-TOFMS detection}

South African wine samples were diluted 1:4 with water and $5 \mathrm{ml}$ were introduced into $20 \mathrm{~mL}$ vials containing 2.4 g of sodium chloride (analytical grade; Sigma, St. Louis, MO). Vials were closed with silicon/Teflon-faced septa and installed in a PAL Combi autosampler (CTC Analytics, Zwingen, Switzerland). An SPME polyacrylate $85 \mu \mathrm{m}$ fibre (Supelco, Bellefonte, PA, USA) was conditioned prior to analysis according to the instructions of the manufacturer. The fibre needle was automatically inserted through the septum of the vial and the fibre was exposed to the headspace for $15 \mathrm{~min}$ at $40^{\circ} \mathrm{C}$, unless indicated otherwise, while being agitated at $250 \mathrm{rpm}$ (agitator cycle: $5 \mathrm{sec}$ on, $2 \mathrm{sec}$ off).

An Agilent 6890N gas chromatograph (Agilent Technologies, Palo Alto, California, USA) was coupled to a Waters GCT Premier time-of-flight mass spectrometer (Micromass, Manchester, UK). Waters MassLynx software (version 4.1) was used to operate the GC-TOFMS system. Helium was used as a carrier gas at a constant flow rate of $1 \mathrm{ml} / \mathrm{min}$. Extracted analytes were desorbed into the GC injection port operated in the splitless mode at $220^{\circ} \mathrm{C}$ for $10 \mathrm{~min}$ to ensure complete desorption and to avoid carry- over between samples. Volatile components were separated on an open-tubular fused silica capillary column (30 m x $0.25 \mathrm{~mm}$ ID) coated with $0.25 \mu \mathrm{m} 5 \%$ phenyl-substituted polydimethylsiloxane (J\&W Scientific, Folsom, CA, USA). The temperature program after injection was as follows: 8 min isothermal at $37^{\circ} \mathrm{C}$, and ramped at $20^{\circ} \mathrm{C} / \mathrm{min}$ to $280^{\circ} \mathrm{C}$. The temperatures of the line-of-sight inlet and ion source were set at $250^{\circ} \mathrm{C}$ and $180^{\circ} \mathrm{C}$ respectively. Detection was performed in scan mode with $\mathrm{m} / \mathrm{z} 35$ to 225 at 4.0 scans per second using perfluoro-tri-n-butylamine as reference.

\section{Headspace SEP extraction and GC-MS detection}

Instead of the stainless steel rods used by Burger et al. (2006) to manufacture SEPs, polyimide-coated fused silica tubing was used as supports (stems) for the PDMS rubber tubing in this study (Burger et al., 2006). The tubing (130 mm x $0.7 \mathrm{~mm}$ O.D.) (Polymicro, Phoenix, USA) was sealed off on both ends using an oxy-methane burner. Using ethanol as lubricating agent, a PDMS sheath was gently slipped over the tip of a stem and positioned about $1 \mathrm{~mm}$ from the one end of the stem. Undiluted wine samples $(50 \mathrm{ml})$ for headspace SEP analysis were placed in glass vials $(100 \mathrm{ml}$ volume) containing $12 \mathrm{~g}$ of sodium chloride and a Pyrex glass-encapsulated magnetic stir bar. Vials were sealed with a phenolic cap adapted with a stainless steel insert (Burger et al., 2006). SEPs, preconditioned as described by Burger et al. (2006) and with the GC septum and septum cap already in place, were introduced into the headspace of samples via the metal inserts. The GC septum caps were tightened and the samples were stirred at $40^{\circ} \mathrm{C}$ for $30 \mathrm{~min}$.

The organic volatiles trapped in the sorptive phase of the SEP were desorbed in the split/splitless GC-injector port of a Carlo Erba QMD 1000 GC-MS instrument operated in the splitless mode at $220^{\circ} \mathrm{C}$, and were separated on a glass opentubular column (40 m x $0.3 \mathrm{~mm}$ I.D.) coated with $0.37 \mu \mathrm{m}$ PS 089 (5\% phenyl-substituted polydimethylsiloxane, DB5 equivalent) using helium as carrier gas at a linear flow velocity of $32.25 \mathrm{~cm} / \mathrm{s}$, which was temperature programmed as follows: $25^{\circ} \mathrm{C}$ isothermal for $5 \mathrm{~min}$, ramped from $25^{\circ} \mathrm{C}$ to $60^{\circ} \mathrm{C}$ at $2^{\circ} \mathrm{C} / \mathrm{min}$ and then from $60^{\circ} \mathrm{C}$ to $280^{\circ} \mathrm{C}$ at $20^{\circ} \mathrm{C} / \mathrm{min}$. The temperatures of the line-of-sight inlet and ion source were set at 250 and $180^{\circ} \mathrm{C}$ respectively. LR-EIMS data were acquired at $70 \mathrm{eV}$ at one scan per second over the mass range $\mathrm{m} / \mathrm{z} 40$ to 120 .

\section{RESULTS AND DISCUSSION \\ Detection of acrolein dimer with headspace SPME-GC- TOFMS}

Analytical detection and quantification of acrolein (Aldrich, Milwaukee, WI, USA) in solution was problematic, as the compound quickly dissipated and could not be detected after $3 \mathrm{~h}$ of contact (data not shown). Several natural derivatives, formed under winemaking conditions, were therefore considered as markers for acrolein detection, including 3-HPA (Table 1). Only the acrolein dimer gave sufficient signal-tonoise ratios for quantification purposes. Identification of target peaks from the total ion chromatogram (TIC) was simplified through the use of extracted ion chromatograms (EICs) (Ryan et al., 2004; Brown et al., 2007). The peak areas of ions 112.05 and 83.05 were used for the quantification of 
the acrolein dimer (Fig. 1). TOF GC-MS provides enough data points for peak integration and quantitative analyses, and allows for accurate mass measurements (Chernushevich et al., 2001). The measured molecular ion for the acrolein dimer (Fig. 2A) was $1 \mathrm{mDa}$ removed from its calculated mono-isotopic mass. A good library match with a reverse match factor of 824 , generated by the widely used NIST mass spectral algorithm, confirmed the identity of the acrolein dimer (Fig. 2B). Match factors are integers in the range 0 to 1000 , with higher numbers indicating a closer match (Bleasel et al., 2003).

\section{Headspace SPME method optimisation}

Operational conditions for the headspace SPME method were studied in a model wine solution $(12 \%$ ethanol, $0.5 \mathrm{~g} / \mathrm{L}$ tartaric acid, $\mathrm{pH}=3$ ) spiked with $5 \mathrm{mM}$ of acrolein (boiling point at $101.3 \mathrm{kPa}=52.1$ to $53.5^{\circ} \mathrm{C}$ ). The temperature of the incubator during extraction is referred to as the extraction

TABLE 1

Natural derivatives of acrolein.

\begin{tabular}{llllc}
\hline Alternate name & Chemical name (IUPAC*) & CAS number & Chemical formula & MW (g/mol) \\
\hline Acrolein & prop-2-enal* & $107-02-8$ & $\mathrm{C}_{3} \mathrm{H}_{4} \mathrm{O}$ & 56.06 \\
Acrolein dimer & 3,4-dihydro-2H-pyran-2-carboxaldehyde* & $77890-80-3$ & $\mathrm{C}_{6} \mathrm{H}_{8} \mathrm{O}_{2}$ & 112.13 \\
3-HPA & 3-hydroxypropanal* & $597-31-9$ & $\mathrm{C}_{3} \mathrm{H}_{6} \mathrm{O}_{2}$ & 74.08 \\
HPA hydrate & $1,1,3$-trihydroxypropane & - & $\mathrm{C}_{3} \mathrm{H}_{8} \mathrm{O}_{3}$ & 92.09 \\
HPA cyclic dimer & 2-(2-hydroxyethyl)-4-hydroxy-1,3-dioxane & - & $\mathrm{C}_{6} \mathrm{H}_{12} \mathrm{O}_{4}$ & 148.16 \\
HPA aldol trimer & - & - & $\mathrm{C}_{9} \mathrm{H}_{18} \mathrm{O}_{6}$ & 22.24 \\
HPA acetal tetramer & - & - & $\mathrm{C}_{12} \mathrm{H}_{22} \mathrm{O}_{7}$ & 278.30 \\
\hline
\end{tabular}
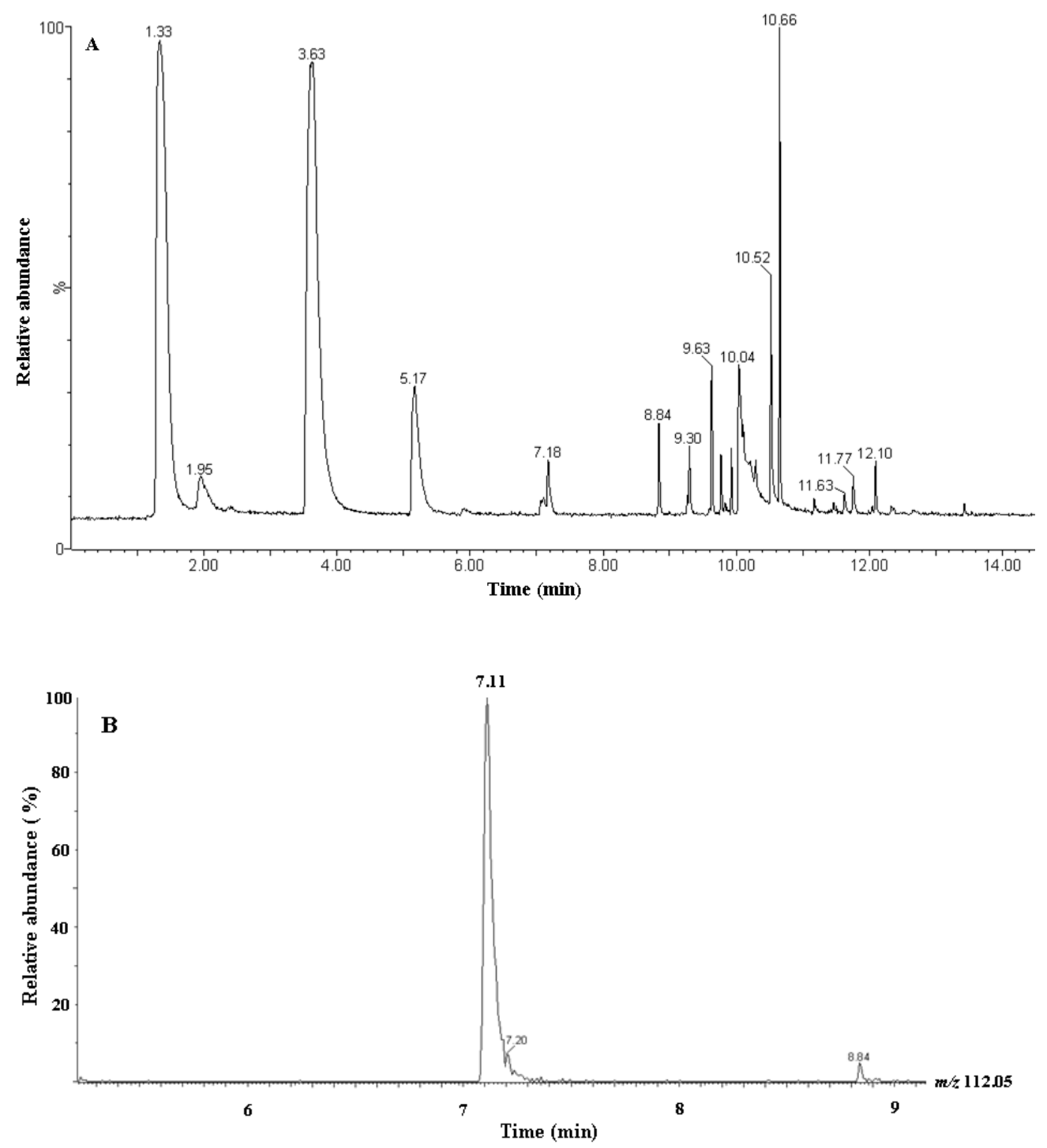

FIGURE 1

Detection of acrolein dimer in white wine by headspace GC-TOFMS. A, Total ion chromatogram (TIC) with acrolein dimer peak eluting at $7.11 \mathrm{~min}$; B, Extracted ion chromatogram for ion at m/z 112.05 (mono-isotopic mass of acrolein dimer). 

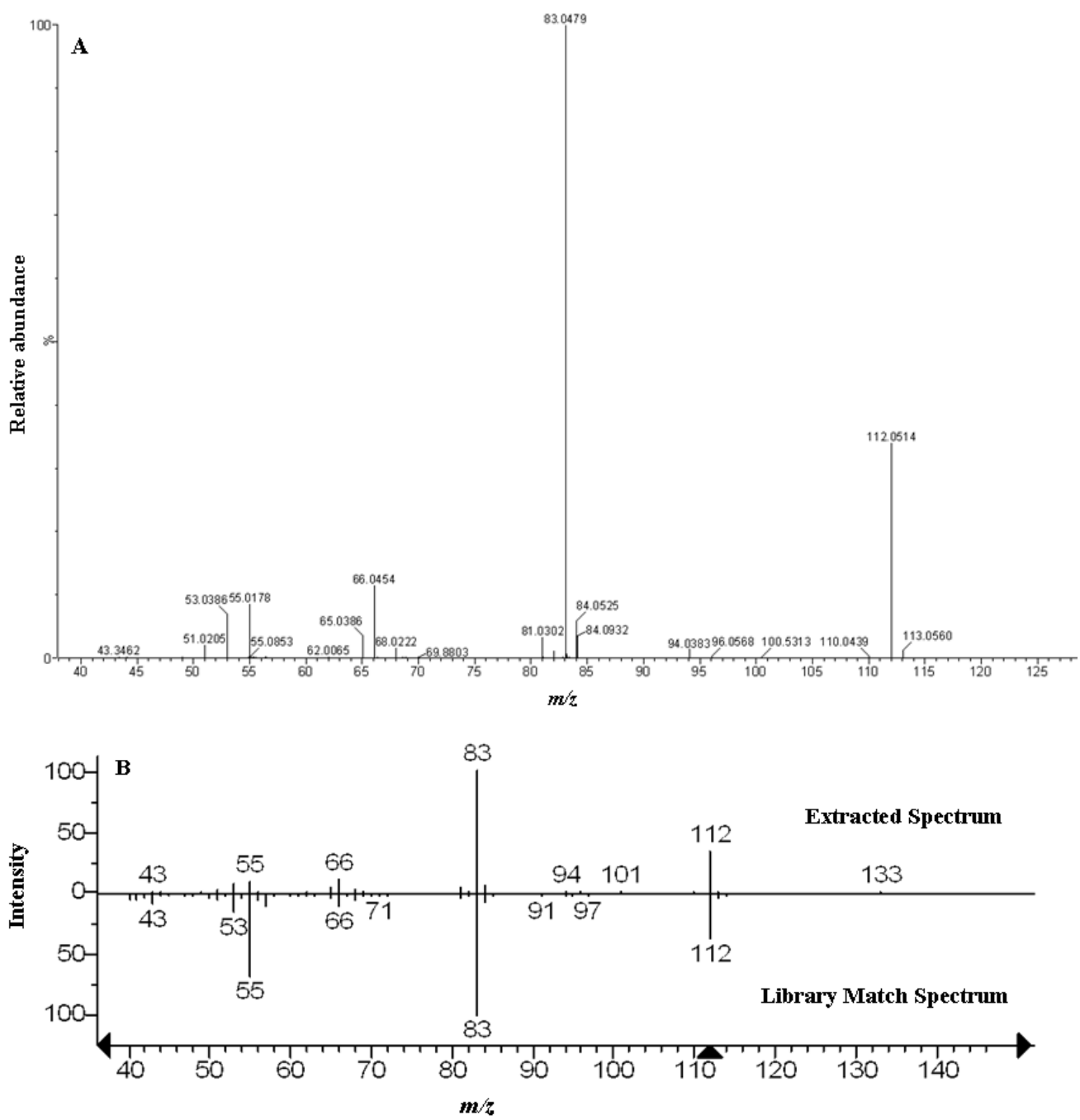

FIGURE 2

Identification of the acrolein dimer. A, Extracted mass spectrum; B, The spectrum aligned with the library mass spectrum of the acrolein dimer (C6H8O2), with a reverse match of 824 using NIST MS Search 2 program and the NIST05 library.

temperature. An increase in extraction temperature from 30 to $60^{\circ} \mathrm{C}$ increased the yield for the acrolein dimer more than threefold (Fig. 3A). Higher temperatures were not evaluated. For practical convenience, all further analysis was performed at $40^{\circ} \mathrm{C}$. Extraction time refers to the duration of exposure of the fibre to the headspace of the sample. Chromatographic response increased approximately 1.5 -fold with an increase in extraction time from 5 to $15 \mathrm{~min}$. (Fig. 3B). The effect of ionic strength on extraction efficiency was tested by the addition of sodium chloride to the diluted wine sample. Concentrations close to saturation point yielded a 10 -fold increase in extraction efficiency (Fig. 3C). Salting-out reduces sample matrix effects and therefore improves method accuracy, while the equilibration time in the headspace vial is shortened ( $\mathrm{Li}$ et al., 2006). Maximum sensitivity was achieved with the split/splitless injection port in splitless mode. Chromatographic response was enhanced more than 15-fold (Fig. 3D).

\section{Headspace SPME-GC-TOFMS method validation}

After establishing the optimal experimental conditions for determining the acrolein dimer in a model wine solution, validation of the headspace SPME-GC-TOFMS was carried out using wine as matrix. Since the TOFMS technique provides excellent mass accuracy (around $1 \mathrm{mD}$ ) and extracts ion chromatograms with a very narrow mass window, background ions were eliminated, which dramatically improves selectivity in a complex matrix such as wine.

Different wine samples were first spiked with acrolein ( $5 \mathrm{mM}$ ) and the dimer was measured after 10 to $12 \mathrm{hrs}$ of contact. Even though headspace analysis minimises interferences resulting from organic compounds in complex matrixes, quantification was shown to be highly dependent on the composition of the individual samples (Fig. 4). Two blended wines (red and white respectively) displayed similar chromatographic responses and were chosen for the validation of the established methodology.

The quantitative linearity of the method was evaluated using a series of standard wine solutions spiked with acrolein (Fig. 5). Lines of best fit, depicting the relationship between the peak responses for the acrolein dimer and the acrolein concentration added, were determined by linear least-squares regression. The results are summarised in Table 2. The calibration curves were linear over the tested concentration range, with correlation coefficients $(\mathrm{R})$ close to 0.99 . The limits of detection (LOD) were obtained by 
the equation $\mathrm{LOD}=\mathrm{KS}_{\mathrm{Y}} / \mathrm{m}$, where $\mathrm{S}_{\mathrm{Y}}$ and $\mathrm{m}$ denote the estimated standard deviation of the intercept and slope of the calibration line respectively, with a $98 \%$ confidence level $(\mathrm{K}=3.3)$ (Miller \& Miller., 1984; Hayashi et al., 2005). The slopes of the analytical curves for the acrolein dimer differed considerably between the two wines, again an indication of the strong matrix effect. Regression analysis and parameters for LOD and LOQ therefore may vary for different wines, depending, for example, on $\mathrm{pH}$ and phenolic content. Data obtained with this methodology should be used taking such factors into consideration.

Precision or repeatability, expressed as relative standard deviation (RSD) of the peak areas, was evaluated by five replicate analyses of wine samples spiked with $5 \mathrm{mM}$ acrolein. Intra-day precision was satisfactory; being below
$10 \%$ (Table 2). When the analyses were repeated seven days later, the RSD values were slightly higher (up to $12.5 \%$ ), but still well within the acceptable range using SPME (Augustin et al., 2005).

The analytical approach involving SPME coupled with GC-MSTOF will benefit from an increase in sensitivity. The potential of SEP as an alternative sorptive extractive technique was therefore investigated. The second-generation SEP probes provide more sorptive stationary phase and a larger surface area (Burger et al., 2011). Since the application of SEP requires modification of the GC-MSTOF instrumentation, the new-generation probe was inserted into the injector port of a conventional quadrupole GC-MS instrument. Data reduction processing was complicated, however, by the co-elution of the dimer and isobutyl acetate
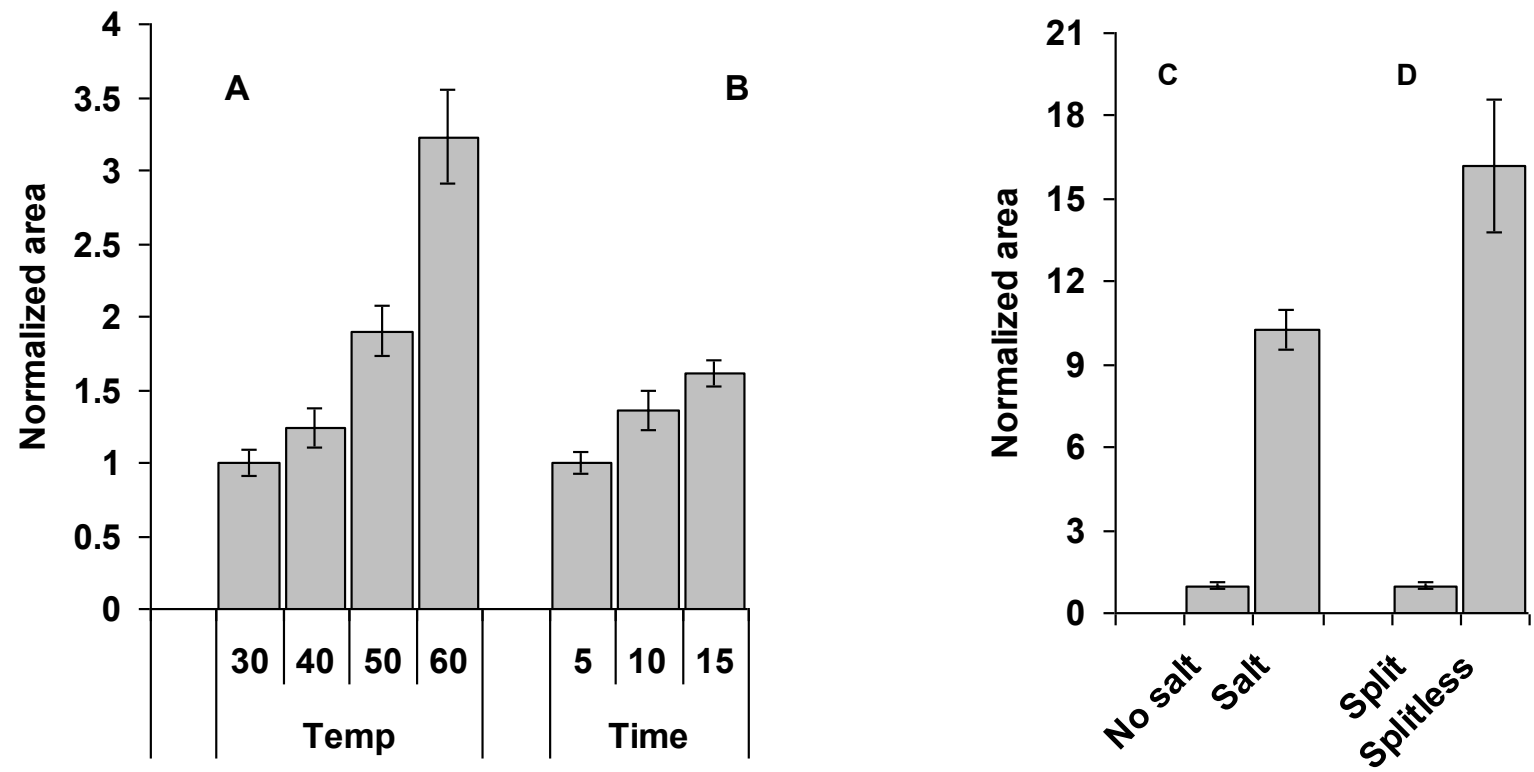

FIGURE 3

Comparison of the operational conditions for the HS-SPME method. A, extraction temperature; B, extraction time; C, ionic strength $(\mathrm{NaCl})$; D, split/splitless GC injector mode (splitting ratio of 1:5). Peak areas are normalised and error bars represent the RSD of the data $(n=3)$.

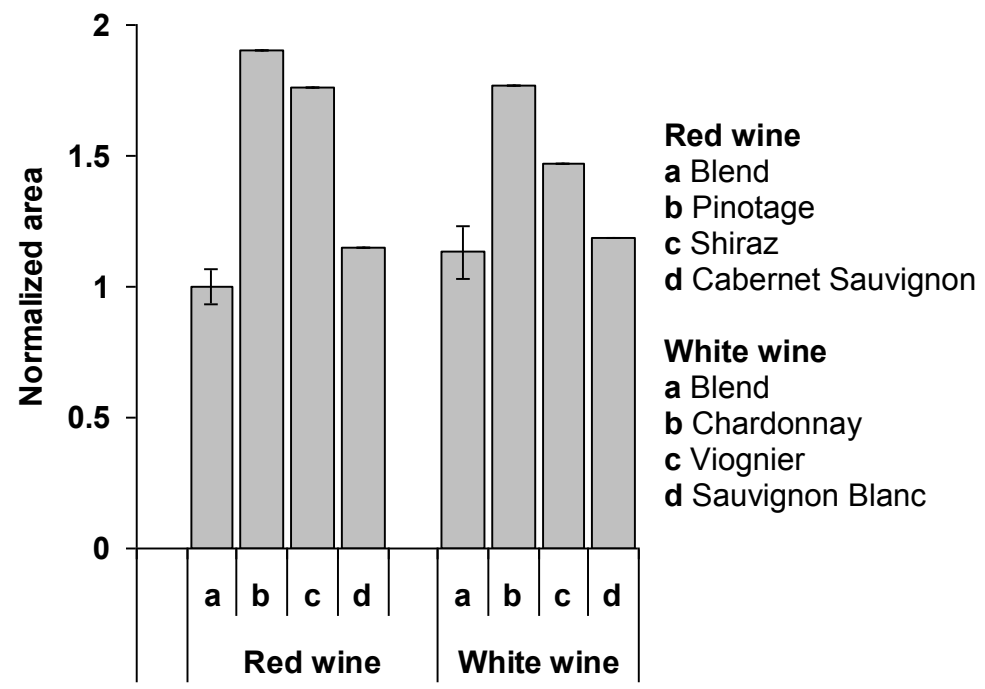

FIGURE 4

Matrix effect in wine analysed by headspace SPME-GC-TOFMS. Wines samples were spiked with 5 mM acrolein and analysed within 10 to $12 \mathrm{hrs}$ at $4^{\circ} \mathrm{C}$. Error bars represent the RSD of the data $(\mathrm{n}=3)$. 
(data not shown). The use of a thick-film capillary column from which the dimer elutes as a sharper peak did not resolve the problem. As for its monomer (Bauer et al., 2010a), conventional GC-MS analysis does not provide sufficient chromatographic resolution for the separation of the acrolein dimer when extracted from complex mixtures. Resolution is affected by the relatively low concentration of the acrolein dimer and the inherent complexity of wine samples. Such complications were circumvented in the SPME analyses on the TOFMS instrument by selecting the ions $\mathrm{m} / \mathrm{z} 112.05$ and 83.05 , which is not achievable with a quadrupole instrument with unit resolution. Considering that the SEP technique is about two orders of magnitude more sensitive than SPME (when only the non-overlapping part of the dimer's peak is used for quantification), a study has been initiated to investigate the performance of SEP when coupled with TOFMS. However, such a route requires an investment in the modification of the GC-MSTOF instrumentation.

\section{Stability of the acrolein dimer in wine}

Few studies have evaluated the content of acrolein in beverages due to complications experienced during analytical detection (Bauer et al., 2010a). The instability of acrolein in aqueous solution presents the biggest hurdle.
Acrolein quickly dissipated from the wine samples and could only be detected within the first $3 \mathrm{hrs}$ after its addition (results not shown). The acrolein content in cider has been also shown to diminish rapidly during the first hours of contact (Ledauphin et al., 2006). The acrolein dimer, on the other hand, was still detectable after 28 days in red wine (Fig. 6). Acrolein is easily polymerised and undergoes a Diels-Alder reaction with itself, yielding the acrolein dimer. Factors initiating polymerisation include the presence of acids (including sulphur dioxide), oxidising agents, or exposure to light and heat. Acrolein and its dimer are highly toxic and have a very reactive free aldehyde group (Smith et al., 1951). Being highly polar, acrolein is furthermore soluble in water and ethanol, with which it reacts slowly and exothermically to give 3-HPA and 3-ethoxypropionaldehyde (3-EPA) respectively. Inter-conversion between acrolein and its derivatives is a complex, highly dynamic and reversible process driven by hydration and dehydration reactions (Bauer et al., 2010a). The reappearance of acrolein or its dimer, or the development of bitterness due to the interaction of acrolein and derivatives with polyphenolics, is of particular concern in wines under storage.

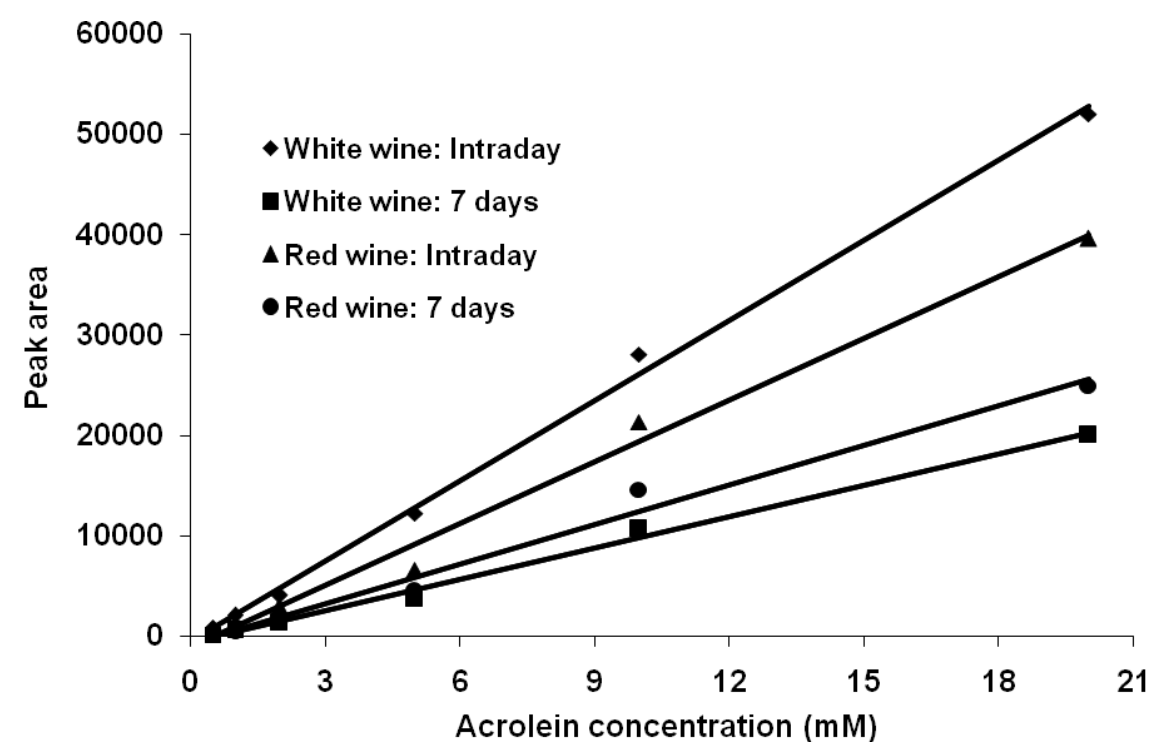

FIGURE 5

Calibration curves for acrolein dimer in wine (red and white) spiked with different concentrations of acrolein and analysed by headspace SPME-GC-TOFMS over time.

TABLE 2

Linear regression parameters of acrolein dimer. Red and white wine samples were spiked with acrolein and analysed with SPME over time.

\begin{tabular}{lcccccccccc}
\hline Sample & Range $(\mathrm{mM})$ & Slope & Intercept & $\mathrm{m}$ & $\mathrm{S}_{\mathrm{Y}}$ & $\begin{array}{c}\text { Data } \\
\text { points }\end{array}$ & $\begin{array}{c}\text { Correlation } \\
\text { coefficient }\end{array}$ & $\begin{array}{c}\text { LOD } \\
(\mathrm{mM})\end{array}$ & $\begin{array}{c}\text { LOQ } \\
(\mathrm{mM})\end{array}$ & $\begin{array}{c}\text { Precision } \\
(\% \mathrm{RSD})\end{array}$ \\
\hline $\begin{array}{l}\text { Intra-day } \\
\text { White wine }\end{array}$ & $0.5-20$ & 2666 & -531 & 68 & 641 & 6 & 0.9974 & 0.35 & 1.06 & 9.4 \\
Red wine & $0.5-20$ & 2050 & -1043 & 99 & 934 & 6 & 0.9907 & 0.35 & 1.06 & 8.5 \\
After 7 days & & & & & & & & & & \\
White wine & $0.5-20$ & 1044 & -610 & 39 & 363 & 6 & 0.9946 & 0.35 & 1.07 & 12.5 \\
Red wine & $0.5-20$ & 1320 & -718 & 78 & 733 & 6 & 0.9862 & 0.32 & 1.06 & 9.7 \\
\hline
\end{tabular}




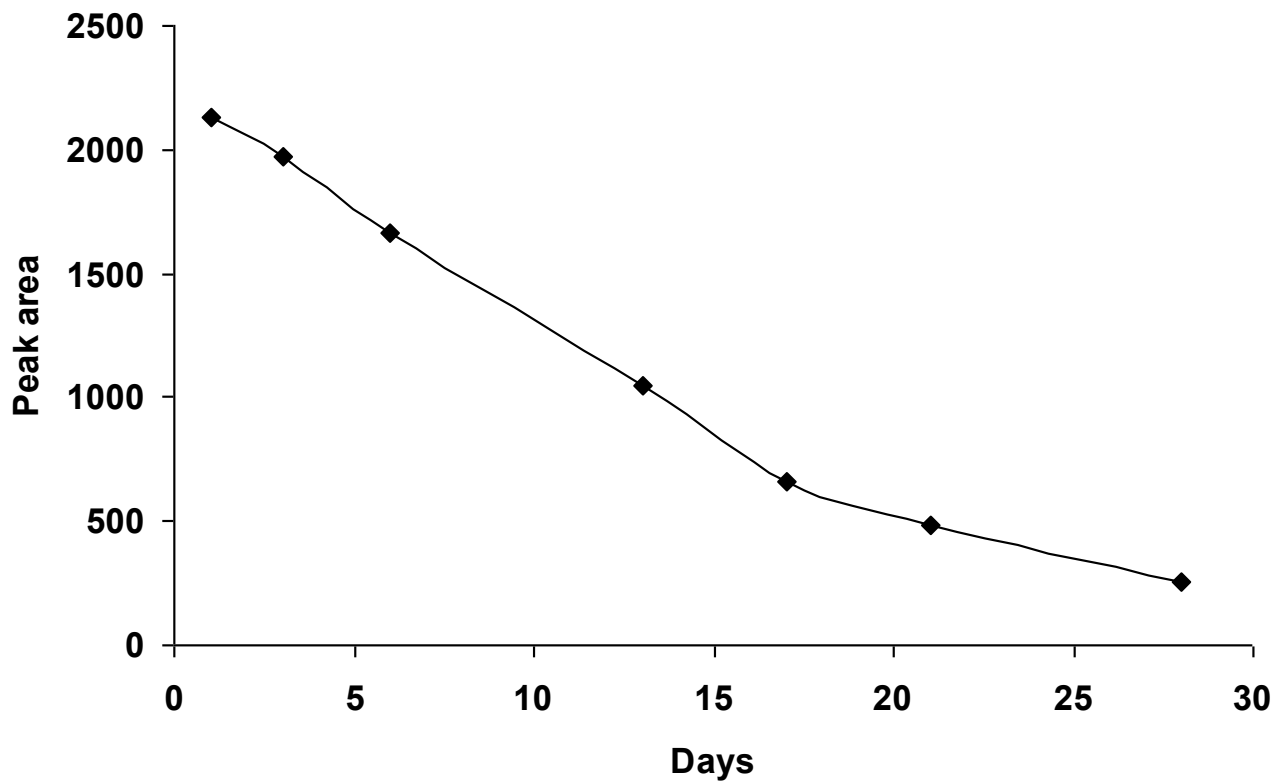

FIGURE 6

Stability of the acrolein dimer. A red wine sample was spiked with $5 \mathrm{mM}$ acrolein, stored at $4{ }^{\circ} \mathrm{C}$, and analysed over time by headspace GC-TOFMS.

\section{CONCLUSIONS}

The analytical detection and quantification of acrolein in solution remains problematic. This study shows that the acrolein dimer can be used as a marker for indicating the presence of acrolein in wines. Due to the instability of the compound, the analytical approach relied on reduced sample preparation steps by applying sorptive sample extraction techniques and direct thermal desorption. Acrolein and its dimer are dangerous substances for the living cell. Further studies on the evolution and transformation of acrolein and its derivatives in solution should be pursued and other compounds produced from this aldehyde should be characterised. A study to fully elucidate the effect of process and maturation conditions on the formation of these compounds in wine is also required. This work lays the analytical foundation for such endeavours, rather than for the routine analysis of acrolein in solution.

\section{LITERATURE CITED}

Arthur, C.L. \& Pawliszyn, J., 1990. Solid phase microextraction with thermal desorption using fused silica optical fibers. Anal. Chem. 62, 21452148 .

Augustin, M.R.R., Park, H., Hong, S., Ryu, J. \& Lee, L., 2005. Determination of mono- to octachlorobiphenyls in fish oil using Florisil adsorption followed by headspace solid-phase microextraction and gas chromatography with time-of-flight mass spectrometric detection. J. Chromatogr. A 1085, 278284.

Bauer, R., Cowan, D.A. \& Crouch, A., 2010a. Acrolein in wine: importance of 3 hydroxypropionaldehyde and derivatives in production and detection. J. Agric. Food. Chem. 58, 3243-3250.

Bauer, R., Du Toit, M. \& Kossmann, J., 2010b. Influence of environmental parameters on production of the acrolein precursor 3-hydroxypropionaldehyde by Lactobacillus reuteri DSMZ 20016 and its accumulation by wine lactobacilli. Int. J. Food Microbiol. 137, 28-31.

Bleasel, M.D., Aldous, S. \& Davies, N.W., 2003. Distinction between melanins derived from different precursors using pyrolysis/gas chromatography/mass spectrometry and the NIST mass spectral search algorithm. J. Anal. Appl. Pyrolysis 70, 649-663.
Brown, S.D., Rhodes, D.J. \& Pritchard, B.J., 2007. A validated SPME-GCMS method for simultaneous quantification of club drugs in human urine. Forensic Sci. Int. 171, 142-150.

Burger, B.V., Le Roux, M. \& Burger, W.J.G., 1990. Headspace analysis: a novel method for the production of capillary traps with ultra-thick stationary phase layers. J. High Resolut. Chromatogr. 13, 777

Burger, B.V., Le Roux, M., Marx, B., Herbert, S.A. \& Amakali, K.T., 2011. Development of second-generation sample enrichment probe for improved sorptive analysis of volatile organic compounds. J. Chromatogr. A, doi:10.1016/j.chroma.2011.01.038.

Burger, B.V., Marx, B., Le Roux, M. \& Burger, W.J.G., 2006. Simplified analysis of organic compounds in headspace and aqueous samples by highcapacity sample enrichment probe. J. Chromatogr. A 1121, 259-267.

Chernushevich, I.V., Loboda, A.V. \& Thomson, B.A., 2001. Special feature tutorial: an introduction to quadrupole-time-of-flight mass spectrometry. J. Mass Spectrom. 36, 849-865.

Esterbauer, H., Schaur, R.J. \& Zollner, H., 1991. Chemistry and biochemistry of 4-hydroxynonenal, malondialdehyde and related aldehydes. Free Radic. Biol. Med. 11, 81-128.

Hayashi, Y., Matsuda, R., Ito, K., Nishimura, W., Imai, K. \& Maeda, M., 2005. Detection limit estimated from slope of calibration curve: an application to competitive ELISA. Anal. Sciences 21, 167-169.

Ledauphin, J., Barillier, D. \& Beljean-Leymarie, M., 2006. Gas chromatographic quantification of aliphatic aldehydes in freshly distilled Calvados and Cognac using 3-methylbenzothiazolin-2-one hydrazone as derivative agent. J. Chromatogr. A 1115, 225-232.

Li, Z , Jacobus, L.K., Wuelfing, W.P., Golden, M., Martin, G.P. \& Reed, R.A., 2006. Detection and quantification of low-molecular-weight aldehydes in pharmaceutical excipients by headspace gas chromatography. J. Chromatogr. A 1104, 1-10.

Miller, J.C. \& Miller, J.N., 1984. Statistics for analytical chemistry. Ellis Horwood, Chichester, New York.

Pasteris, S.E. \& Strasser de Saad, A.M., 2009. Sugar-glycero cofermentations by Lactobacillus hilgardii isolated from wine. J. Agric. Food Chem. 57, 3853-3858

Raynie, D.E., 2006. Modern extraction techniques. Anal. Chem. 78, $3997-$ 4003 
Rentschler, H. \& Tanner, H., 1951. Das bitterwerden der Rotweine. Mitt. Lebensm Unters. Hyg. 42, 463-475.

Ryan, D., Shellie, R., Tranchida, P., Casilli, A., Mondello, L. \& Mariot, P., 2004. Analysis of roasted coffee bean volatiles by using comprehensive two-dimensional gas chromatography time-of-flight mass spectrometry. J. Chromatogr. A 1054, 57-65.

Seaman, V., Charles, M. \& Cahill, T., 2006. A sensitive method for the quantification of acrolein and other volatile carbonyls in ambient air. Anal. Chem. 78, 2405-2412.

Smith, C.W., Norton, D.G. \& Ballard, S.A., 1951. Reactions of acrolein and related compounds. II. Addition of unsaturated esters and of methacrylonitrile. J. Am. Chem. Soc. 73, 5270-5272.
Takamoto, S., Sakura, N., Namerab, A. \& Yashiki, M., 2004. Monitoring of urinary acrolein concentration in patients receiving cyclophosphamide and ifosphamide. J. Chromatogr. B 806, 59-63.

Takamoto, S., Sakura, N., Yashiki, M. \& Kojima, T., 2001. Determination of acrolein by headspace solid-phase microextraction gas chromatography and mass spectrometry. J. Chromatogr. B 758, 123-128.

Uchida, K., Kanematsu, M., Morimitsu, Y., Osawa, T., Noguchi, N. \& Niki, E., 1998. Acrolein is a product of lipid peroxidation reaction. J. Biol. Chem. $273,16058-16066$ 